\title{
Accesible co-creation tools for people with intellectual disabilities: working for and with end-users
}

\begin{abstract}
Rosa Almeida ${ }^{a}$, Raquel Losada Durán ${ }^{b}$, Teresa Cid Bartoloméc, Andrea Giaretta ${ }^{d}$, Alice Segalina $^{\mathrm{e}}$, Anna Bessegato ${ }^{\mathrm{f}}$, Simone Visentin ${ }^{\mathrm{g}}$, Sandra Martínez-Molina ${ }^{\mathrm{h}}$, Jorge Garcés $^{i}$, Valentina Conotter ${ }^{j}$, Davide Lissonik ${ }^{k}$, Dana Migalioval, Natalija Olèsova ${ }^{\mathbf{m}}$, Aidas Gudavičius ${ }^{\text {, }}$, Miguel Lancho ${ }^{\circ}$

${ }^{a}$ Fundación INTRAS, Valladolid, Spain, rra@intras.es, ${ }^{b}$ Fundación INTRAS, Valladolid, Spain, rld@intras.es, ${ }^{\mathrm{c}}$ Fundación INTRAS, Valladolid, Spain, tcb@intras.es, ${ }^{\mathrm{d}}$ Cooperativa Margherita, Sandrigo, Italy, europacoop@ cooperativamargherita.org, ${ }^{\text {}}$ Cooperativa Margherita, Sandrigo, Italy, alice.segalina@cooperativamargherita.org, ${ }^{\mathrm{f}}$ Cooperativa Margherita, Sandrigo, Italy, anna.bessegato@ cooperativamargherita.org, ${ }^{\mathrm{g}}$ University of Padua, Italy, simone.visentin@ unipd.it, ${ }^{\text {h }}$ Polibienestar Research Institute, University of Valencia, Valencia, Spain, Sandra.martinezmolina@uv.es, 'iPolibienestar Research Institute, University of Valencia, Valencia, Spain, Jordi.garces@uv.es, jSOCIALIT, Trento, Italy, valentina.conotter@socialit.it, ${ }^{k}$ SOCIALIT, Trento, Italy, davide.lissoni@ socialit.it, ${ }^{\mathrm{l} V}$ Viltis, Vilnius, Lithuania, mig@ viltis.lt, ${ }^{\mathrm{m}}$ Viltis, Vilnius, Lithuania, viltis@ viltis.1t, ${ }^{\mathrm{n}}$ Viltis, Vilnius, Lithuania, aidas.gudavicius@ viltis.lt, ${ }^{\circ}$ Autismo Burgos, Burgos, Spain, miguellancho@autismoburgos.org
\end{abstract}

\section{Abstract}

In a world defined by rapid change, the search for solutions to societal challenges has become more complex calling for new paradigms of innovation focused on collaborations with the community and users. Cocreation approaches in the design and production of a service or product can bring low-cost innovation and unique and personalized customer experiences leading to user acceptance of a product or service.

Under a co-creation perspective, the participatory approach developed in the MINDInclusion project aims to improve the inclusion of people with intellectual disabilities into public places and society by using a co-created online tool based on personal experiences of people with disabilities. Paying special attention to the Design thinking method, the main goal of this experience was to co-create cognitive accessible design tools that guide the collection of users and other stakeholders experiences in the process of defining problems and solutions.

To this end, 14 researchers and educators worked defining together a set of guiding exercises and design thinking methods for the 4 co-design cycles. 
As a result two tools were developed to gather information to recreate as a final output "personas scenarios", an "empathy map" and expected "use scenarios". The former was an adapted game board about public places based on the traditional monopoly game and the latter a diary with a set of activities that will facilitate the collection of contextual information.

Previous experiences have shown that co-design process can promote greater social cohesion, acceptance and empowerment. Working with people with intellectual disability presents several challenges since the co-creation process needs to be cognitive accessible. However, the tools created under this experience can be extrapolated to other contexts.

Keywords: Co-creation, intellectual disability, social inclusion, cognitive accessibility

\section{Introduction}

In a world defined by rapid change, the search for solutions to societal challenges has become more complex calling for new paradigms of innovation focused on collaborations with the community and users. Co-creation approaches in the design and production of a service or product can bring low-cost innovation and unique and personalized customer experiences leading to user acceptance of a product or service. However, working with endusers can be a challenge, especially when working with groups that are more vulnerable.

Under the capability approach (Nussbaum 1997; Sen 1993), the Mind Inclusion 2.0 project aims to widen the opportunities of people with intellectual disabilities to be involved in the society. To this end, an innovative web platform will be developed, contributing to the sustainable and inclusive involvement of disabled people in the society. The innovation relies on the participation of people with disabilities during the design and production of the web platform, meaning that all the co-creation process must be cognitive accessible for people with intellectual disabilities and mindful with participants requirements for participation.

This paper shows an experience in the design of some cognitive accessible tools that can guide the collection of users and other stakeholders' experiences, and help to know their motivations, preferences, problems and potential solutions that people experience in public places. 


\section{Co-creation methodologies}

Paradigms focused on establishing close and active collaborations with the community and users are increasing. This change in the relationship between citizens/users and researchers, developers and companies have been preceded by a large number of concepts, guiding methodologies, approaches and frameworks such as user-centred and user-drive design. Nowadays, Co-Creation, integrating Co-Design and Co-Production, has been regarded as an unquestionable strategy for socio-health innovation, which is able to deliver innovations designed "with" and "by" the people, enabling the participation of those affected by the design.

To implement a strong participatory approach and co-creation methodologies the project focused on the learned experience with the Mindful design framework incorporates principles of Mindfulness in a Design Thinking that aims a Experience-led design process (Peters, Hansen, McMullan, Ardler, Mooney and Calvo, 2018; Wodehouse and Tzvetanova, 2015). Mind Inclusion aims to ensure user involvement in the design activities, in the form of both direct and indirect participation in the Agile development of the webplatform (Kautz, 2010).

Under the Mindful design framework, mindfulness in a design context refers "to the attentiveness of the user towards the consequences of their actions performed with an object, encouraging behavioural changes and adaptation by reconsidering actions and their causes" (Niedderer 2007: 4). This integrated co-design methodology covers three stages of data collection, design development, and implementation evaluation in a project. Recent experiences have applied this framework to support the participation of people with dementia in co-creation process in a successful way (Niedderer et al., 2017). On the other hand, Design Thinking (DT) is a method intending to create solutions that go beyond the ones developed by conventional analytical methods, based on creativity and systemic thinking (Koria, Graff, \& Karjalainen, 2011). The term is also defined as the way designers think (McKilligan, Dhadphale, Ringholz, 2017). The main goal of this approach is to challenge the way innovation happens considering the needs and the perspective of endusers during the design and development process. In particular, this method consists of 5 steps: a) "Empathize"aiming to learn about the audience for whom we are designing; b) "Define": focusing in redefining the initial user needs/ cases and design process goals; c) "Ideate":intending to brainstorm and come up with creative solutions to the defined needs; d) "Prototype":building a representation of one or more ideas; e) Finally the "Test" were researchers return to the original user group and test the prototype ideas for feedback. 
In turn, Agile Method is generally adopted to increase development performance in terms of continuous, efficient and effective adaptation in user requirements changes by measuring and evaluating the status of a project (Lee \& Xia, 2010). It focuses on the fundamental assumption that adaptive software can be developed by small teams using the principles of continuous design improvement and testing based on rapid feedback and change.

Apart from these theoretical perspectives and methods, nowadays the use of hybrid methodologies such the one presented is gaining importance. Specifically, Mind Inclusion 2.0 project will pay special attention to the combination of the Design Thinking method and Agile approach. Thus, while Design Thinking will allow to identify unmet needs of endusers, Agile approach will enable delivering a partially functional prototype to collect feedback, validate our assumptions and readjust.

\subsection{Challenges when applying co-creation methodologies: cognitive accessibility}

Beyond the advantages attributed to co-creation methodologies, its application might suppose a challenge, especially when working with people with intellectual disabilities since they can be a heterogeneous group with different health, activeness, social involvement as well different problems related to a wide rage of life aspects. In result, the main challenge when working with people with disabilities is to make the co-creation process accessible to their existent cognitive and communicative barriers.

Cognitive accessibility applied to to enviroments and locations means that people can understand what characterizes each environment, its category, functionality, values and norms, and people' use it and roles (Belinchón et al., 2014; Plena Inclusión, 2008). All the above mentioned considerations regarding accessibility are an important, since the elimination of obstacles and barriers to accessibility are rights established in the Covention on rights of persons with disabilities (2006) in Art. 9, 19 and 20. Moreover, cognitive accessibility in spaces, services, and products can benefit the society as a whole.

Taking this into account, the participatory approach developed in the Mind inclusion project 2.0, that brings together principles of the Mindful Design Framework and Agile elicitation and development, aims to improve the inclusion of people with intellectual disabilities into public places enabling social participation through the use of a co-created online tool. This web-tool is being designed based on three pillars of information: i. base research on cognitive accessibility; ii. people with disabilities' personal experiences translated into requirements and preferences for interaction and functionality; iii. complementing with professionals accumulated experience and contexts analysis. For this process was essential to co-create cognitive accessible design thinking tools that guide the consultation and co-creation approach with collection of relevant insights from users and 
other stakeholders in the process of defining problems and ideate solutions (corresponding to the first 3 steps of Design Thinking method: empathize, define, ideate) for requirements elicitation.

\section{Methodology}

The Mind Inclusion 2.0 project co-creation process was structured in 2 co-design and 2 coproduction sessions with users. In the planning phase two cognitive accessible design thinking tools were co-created to support information gathering in the co-design sessions. The aim was to recreate as a final output "personas scenarios", an "empathy map" and concrete "use scenarios" that will guide the development of Mind inclusion web platform.

The objective of developing "personas scenarios" is to help to define problems that users face when accessing public places, gathering information related to individual interests and barriers find in the near context. Thus, tools that should be developed need to collect information about aspects of a real or imagined case of intellectual disabled person including the following: i. Life-context and motivations: about social engagement and interaction; ii. Needs or aids; iii. Likes: centred on self-realization, preferences about places and social activities; iv. Worries: reflecting experiences and/or emotions; v. Wishes: reflecting how support the persona may like to receive; desirable improvements for making places and activities more friendly.

In the case of the empathy map that serves to complement "personas", this tool helps to create a common vision about users' common thinking and feeling in a pre-elabored situation, as well as motivations, attitudes, aspects of interaction, and beliefs. Therefore, the following dimensions of information are needed: i. Tasks that users are trying to complete and questions they need to answer; ii. Influences: people, things or places that might influence in the user's acts and how they influence; iii. Feelings about an experience; iv. Pain points to overcome; v. Overall goal to achieve.

To this end, 14 researchers and educators worked defining together a set of guiding exercises and design thinking methods for the 2 co-design cycles that will involve people with disabilities, caregivers, social and health professionals and managers of public spaces. In order to participate, people with disability need to adults and be able to communicate and express preferences with or without help of a facilitator, able to give their consent or agree with participation and have low-to-mild degree of disability. 


\section{Results}

During the sessions two tools were co-created to gather information to simulate "personas scenarios" and an "empathy map".The former was an adapted game board about public places based on the traditional monopoly game and the latter a diary with a set of activities that facilitate the collection of contextual aspects that influence motivation for visiting places, access and general experience of the users.

\subsection{Mind Inclusion game board}

The final objective of the Mind Inclusion game is to gather information about the aforementioned dimensions: a) Life-context and motivations; b) Needs or aids used; c) Likes; d) Worries; e) Wishes. To this end, a board with different squares related to the participation in public places was developed.

\subsubsection{Description}

The Mind Inclusion game is a board game similar to the traditional monopoly but adapted for people with intellectual disabilities. The game is composed of a board, two dices (one ordinary dice and a specific dice with pictures), two stacks of cards and a participant marker for each player.

In the board game there are several types of game boxes: 1. Places; 2. Blank boxes; 3 . Collective Challenges; 4. Individual Challenges.

The participants will have to choose four different places from the list or images made available. This places will be added on the "places boxes". Each selected place will appear 4 times in the game to let the participant have opportunity to remind experiences in such place.

All players start the game with the markers in the first starting game box. Depending on the game box in which the participant market falls the activity or the information required will vary according to:

- Places boxes. The participant need to throw a special dice for the game. Depending on the picture on the dice's face, the user will need to answer some of these questions: a) What would you like to find in ... (the place represented)... to be happy?; b) What makes you feel GREAT in ...?; c) What is your 1st thought visiting... ?; d) What do you need to enjoy ... ?; e) Share a funny experience in ...f) What makes you feel BAD in ...? 
- Individual Challenge: in which each participant will take a card from the stack of cards answering a question or doing a creative exercise.

- Collective Challenge: at the beginning of the session the group decide the collective challenges.

\subsection{Mind Inclusion diary}

The Mind Inclusion Diary constists of a set of activities to be performed at home/activity center in order to reflect over leisure time and places to visit.

\subsubsection{Description}

The diary consists of 6 assignments:

- Activity 1-What do you like/don't like when you go out?: User should paste some pictures (from photographs, magazines, images...) on the diary.

- Activity 2- My feelings: users will reflect over feelings that they can have when they go out. This reflection will be made by using the stickers/stamps on each place of the diary.

- Activity 3-Rating places: this activity is made up of three sections: a)To select the places; b) people they go with; c) To rate the places from 1 to 5 .

- Activity 4-Visiting a new place: users will need to find out places presents in their town.

- Activity 5- Explore a new place: we ask to the users to go to at least one place, which is new for them.

- Activity 6-What are the things or people that make you feel ok in new places?: There are several places and stickers and they need to paste "V" above the places that users found.

\section{Conclusions}

The group considered in the co-creation process different cognitive accessibility recommendations and guidelines such as "Mindful Design Principles" and facilitators for verbal and non-verbal communication. Previous experiences have shown that co-design process with users are able to promote greater social cohesion and acceptance, apart that the own process can be empowering. However, working with people with intellectual disability presents several challenges since the co-creation process needs to be cognitive accessible 
and mindful in all the stages, from planning to evaluation of participation. This experience resulted in the creation of two cognitive accessible tools for supporting co-design processes withpeople with cognitive disabilities or with low to moderate cognitive impairment, and with potential to be extrapolated to other users groups participating in research and cocreation environments.

\section{Acknowledgments}

The findings obtained in this paper are part of the project entitled Mind Inclusion 2.0 funded by the European Commision under the Erasmus + program.

\section{References}

Belinchón, M., Casas, S., Díez, C., Tamarit, J. (2014). Accesibilidad cognitiva en los centros educativos. Colección Guías prácticas de orientaciones para la inclusión educativa. Madrid: Secretaria General Técnica. Sudbidrección General de Documentacion y Publicaciones.

Kautz K. (2010). Participatory Design Activities and Agile Software Development. In: Pries-Heje J., Venable J., Bunker D., Russo N.L., DeGross J.I. (eds) Human Benefit through the Diffusion of Information Systems Design Science Research. TDIT 2010. IFIP Advances in Information and Communication Technology, vol 318. Berlin: Springer.

Koria, M., Graff, D., Karjalainen, T.M. (2011). Learning design thinking: International design business management at Aalto University. REDIGE, 2(1), 1-20.

Lee, G., and Xia, W. (2010). Toward Agile: An Integrated Analysis of Quantitative and Qualitative Field Data on Software Development Agility. MIS Quarterly, 34(1), 87-115.

McKilligan, S., Dhadphale, T., Ringholz, D. (2017). Speed Dating with Design Thinking: An empirical study of managers solving business problems with design. Retrived from: https://scholar.uc.edu/concern/articles/mc87pq263?locale=en

Niedderer, K. (2007). Designing Mindful Interaction: The Category of the Performative Object. Design Issues, 23(1), 3-17.

Niedderer, K., Tournier, I., Colesten-Shields, D., Craven, M., Gosling, J., Garde, J.A., Bosse, M., Salter, B., Griffioen, I. (2017) Designing with and for People with Dementia: Developing a Mindful Interdisciplinary Co-Design Methodology. In: Proceedings of the IASDR international Conference 2017, Cincinnati, USA, 31October-3 November 2017. doi:10.7945/C2G67F Proceedings

Nussbaum, M.C. (1997). Capabilities and Human Rights, 66 FordhamL. Rev. 273. Retrived from: http://ir.lawnet.fordham.edu/flr/vol66/iss $2 / 2$

Peters, D., Hansen, S., McMullan, J., Ardler, T., Mooney, J., Calvo, R.A. 2018. "Participation is not enough": towards indigenous-led co-design. In Proceedings of the 30th Australian Conference on 
Rosa Almeidaa, Raquel Losada Duránb, Teresa Cid Bartoloméc,, Andrea Giarettad, Alice Segalinae, Anna Bessegatof, Simone Visenting, Sandra Martínez-Molinah, Jorge Garcési, Valentina Conotterj, Davide Lissonik, Dana Migalioval, Natalija Olésovam, Aidas Gudavičiusn, Miguel Lanchoo

Computer-Human Interaction (OzCHI '18). ACM, New York, NY, USA, 97-101. DOI: https://doi.org/10.1145/3292147.3292204

Plena Inclusión. (2008). Guía de evaluación de accesibilidad cognitiva de entornos. Madrid: Plena Inclusión España.

Sen, A. (1993). Capability and Well-being. In Nussbaum and Sen (Eds.), The Quality of Life (pp. 3053) .Oxford: Clarendon Press.

United Nations. (2006). Convention on the Rights of Persons with Disabilities. Retrieved from: https://www.un.org/development/desa/disabilities/convention-on-the-rights-of-persons-withdisabilities.html

Wodehouse, A., \& Tzvetanova Yung, S. (2015) Special issue on interaction and experience design. Journal of Engineering Design, 26, 95-98, DOI: 10.1080/09544828.2015.1030373 